\title{
AN UNUSUAL INJURY OF THE CERVICAL SPINE CAUSED BY A FORK LIFT*
}

By P. Dro, M.D., B. Huber, M.D., P. Dollfus, M.D., and R. Gschaedler, M.D. Traumatology Unit, Colmar and Centre de Readaptation, Mulhouse, France

\begin{abstract}
A case of very unusual aetiology is reported. A severe traumatic injury of the cervical spine was associated with a suspended bilateral phrenic nerve paralysis, with limited sensory involvement, and weakness of the muscles of the right upper limb. The neurological status was otherwise normal, apart from slight weakness of the left upper limb. Artificial ventilation was necessary. Respiratory recovery was slow. The neural aetiology is discussed in relation to spinal cord and/or root involvement.
\end{abstract}

Key words: Spinal cord injury; Phrenic nerve paralysis; Respiratory insufficiency; Fork lift.

\section{Introduction}

HigH cervical spinal cord lesions, especially at the level of $\mathrm{C}_{\mathrm{I}}-\mathrm{C}_{2}$ vertebrae, are known to cause immediate respiratory insufficiency, due to the absence of all motor respiratory functions below the level of the lesion. This involvement, complete or incomplete, includes that of the phrenic nerve.

Clinical observations have shown (Guttmann, 1973) that in lesions at, or above $\mathrm{C}_{5}$, the weakness of the biceps and the deltoid is associated with that of the ipsilateral diaphragm. This is due to the proximity of the nuclei of these muscles with those of the phrenic nerve $\left(\mathrm{C}_{3} / \mathrm{C}_{4} / \mathrm{C}_{5}\right)$.

Diagnostically the injury to the cervical spine can be difficult to locate, futhermore, it can be difficult to differentiate between damage to the spinal cord, nerve roots or a high cervical nerve plexus, as far as the dissociation between spinal cord and associated spinal nerve roots or a high cervical nerve plexus damage is concerned.

We wish to give the following case report, mainly because of very unusual traumatic aetiology and the still uncertain diagnosis concerning the exact neuropathological damage.

\section{Case report}

A 30-year-old man, whilst at work (23 February 1978), was trying to secure a load, which fell backwards from the forks of his elevator cart. To do so, he passed through the opening situated below the roof of his fork lift and behind the dash-board front. This was a very hazardous manoeuvre indeed, as he slipped downward, and his left foot hit the elevator controls of the vehicle situated on the floor, and at the same time his right foot put into action the other controls situated next to the steering wheel. This resulted in a backward movement of the stem supporting the forks, and at the same time, the elevating mechanism of the vehicle was started; this, in fact, saved his life by hanging him up, and taking his feet from the controls. Everything then stopped functioning, but his head and neck remained trapped and rotated between the stem and the roof of the fork lift.

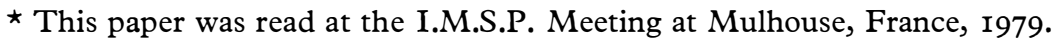


He lost consciousness for a short time. The patient was transferred by ambulance to the Traumatology Unit at Colmar. Radiographs of the cervical spine showed a fracture dislocation of $\mathrm{C}_{4} / 5$ with a fracture of $\mathrm{C}_{5}$, a unilateral articular subluxation of $\mathrm{C}_{4} / 5$ on the right side and fractures of $\mathrm{C} 6$ and $\mathrm{C}_{7}$ spinous processes (Fig. I $a$ and $\mathrm{i} b$ ). Clinically, there was marked weakness of the deltoid and biceps muscles on the right side, and to a lesser degree, of the brachioradialis also on this side. A zone of hypo-aesthesia and hypo-algesia was found in the $\mathrm{C}_{3}$ and $\mathrm{C}_{4}$ dermatomes on the same side. There was only slight motor involvement of the deltoid and biceps on the left side. No motor involvement was found below the level of the spinal lesion. The deltoid, biceps and brachio-radialis reflexes were absent in the

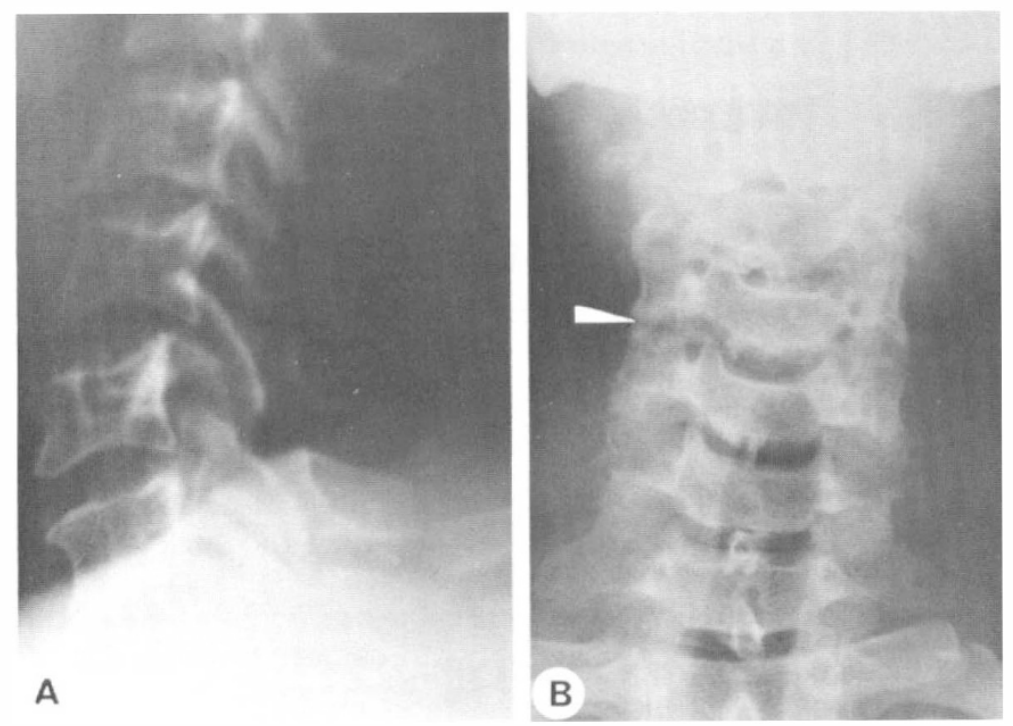

FIG. I $a$

Reduced fracture-dislocation of $\mathrm{C}_{4}-5$. Fracture of $\mathrm{C}_{5}$. Fractures of $\mathrm{C}_{6}$ and $\mathrm{C}_{7}$ spinous processes.

FIG. I $b$

Shows that the dislocation was more important on the right side.

right upper limb. The reflexes in the lower limbs were normal. There was no other sensory disturbance; and no involvement of the urinary bladder or bowel. It must be stressed that the neurological examination was, in fact, carried out in an emergency situation, as the patient's breathing gradually became impaired; and he was rapidly transferred to the Resuscitation Unit for further observation and treatment. Over the next 24 hours, his respiratory insufficiency gradually became worse, the blood gases deteriorated, and he was placed on controlled mechanical ventilation. A nasotracheal tube was inserted. The following day, there was no apparent neurological change, except that the patient was calmer and more co-operative. The neurological sensory examination showed (Fig. 2) that above the area of hypo-algesia and hypo-aesthesia in $\mathrm{C}_{3}$ and $\mathrm{C}_{4}(b)$ there was a zone of complete anaesthesia and analgesia covering the $\mathrm{C}_{2}$ cutaneous area $(a)$. The trigeminal sensory territory was unaffected. This sensory disturbance 
subsided very quickly, leaving only hypo-aesthesia and hypo-algesia in the $\mathrm{C}_{3}$ and $\mathrm{C}_{4}$ dermatomes, which gradually disappeared over the next 2 months. Functional radiographs of the chest showed marked paralysis of the right diaphragm, and to a lesser degree of the left side of the diaphragm. He was extubated i 5 days later and was transferred to the Mulhouse Unit. His vital capacity improved from $\mathrm{I}, 200 \mathrm{mls}$ to over $2,200 \mathrm{mls}$ as did the motor involvement in the right upper limbs by the time he was discharged. Precise motor muscle assessment was difficult during the first 3 months, because of the cervical injury, but it was estimated that apart from the deltoid and biceps and the brachio-radialis muscles, there was also weakness of the rhomboid, teres major, teres minor, infraspinatus and the serratus anterior. (A plastic neck and head collar was insufficient to keep his cervical subluxation properly reduced and he was immobilised in a head, neck and chest plaster of Paris cast). At this time the reflexes were weak in the right upper limb

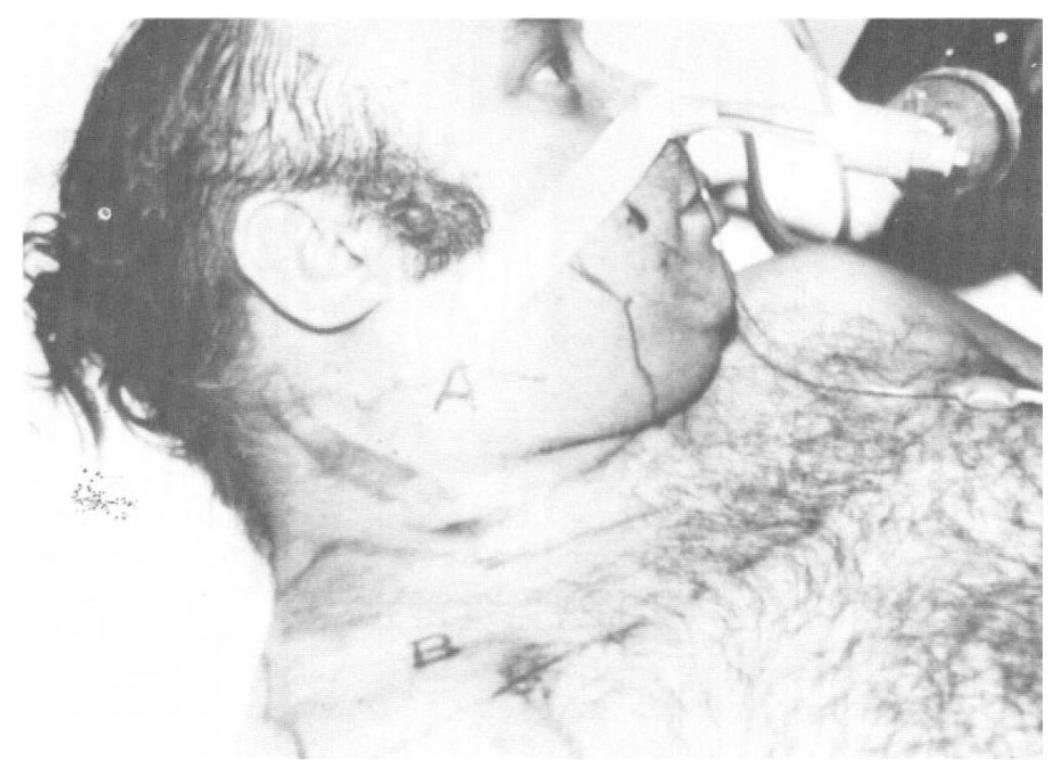

FIG. 2

Photograph showing the sensory changes; and showing 'the evidence of the strangulation'.

but contrastingly finger flexor reflexes were present as well as a positive Hoffmann reflex. The reflexes of the left upper limb were normal, but there were positive finger flexor and Hoffmann reflexes. All the other reflexes were normal.

After I4 months, the motor functions were almost normal in the right upper limb, apart from slight remaining weakness and atrophy of the deltoid, biceps and brachio-radialis muscles. There were no changes in the reflexes since the last examination, except that in the left upper limb there was hyper-reflexia at all levels and a left-sided Babinski reflex which was not present in the previous examinations. Vital capacity at the time of the last examination (April 1979) was $2,800 \mathrm{mls}$. The dynamic functional radiographs of the diaphragm showed a return to normality (Fig. 3a, 23.2.1978; Fig. $3 b$, 28.2.1978; Fig. 3c, 27.4.1979).

He has returned to work, but not on a fork lift! 

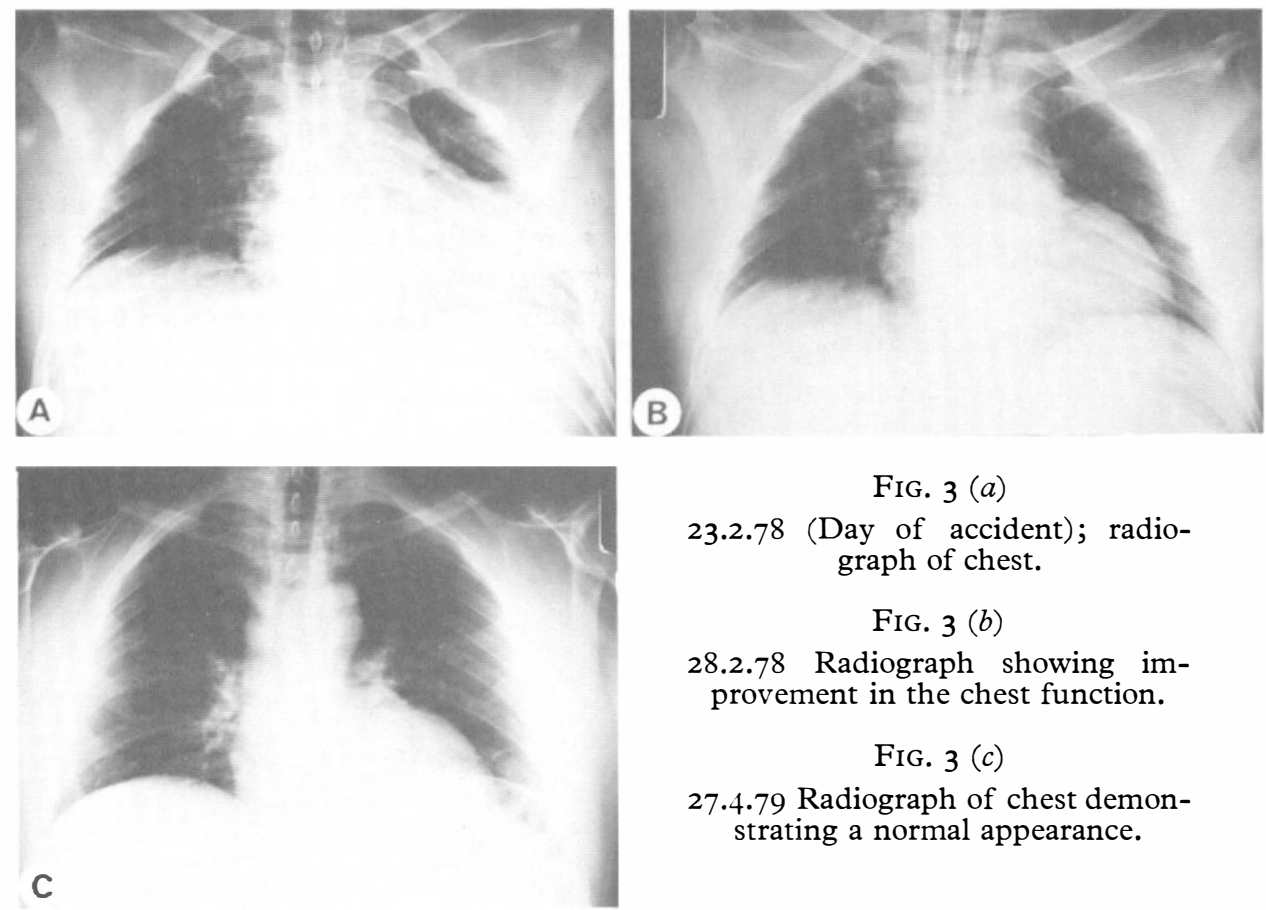

FIG. $3(a)$

23.2.78 (Day of accident); radiograph of chest.

FIG. 3 (b)

28.2.78 Radiograph showing improvement in the chest function.

FIG. 3 (c)

27.4.79 Radiograph of chest demonstrating a normal appearance.

\section{Discussion}

The literature is scarce regarding traumatic 'isolated' bilateral lesions of the phrenic nerves. As far as cervical spinal cord injuries are concerned, severe motor, sensory and sphincter disturbances below the level of the lesion invariably occur. The neural damage in this patient could be either that of a bilateral nerve root, or of a high plexus lesion caused by all the different traumatic mechanisms involved (flexion, rotation, retroflexion and elongation). Mechanical or vascular, injury at the level of the spinal cord cannot be totally excluded, especially in the light of the delayed changes in the reflexes in the left upper limb, evoking an upper motor neurone lesion, with a lower motor neurone type of lesion on the right side. Another mechanism that can be considered is direct phrenic nerve damage caused by a strangulation mechanism. Suspicious traces on the skin can be seen in the photograph (Fig. 2).

\section{Conclusion}

Careful observation of respiratory function must be considered in those patients who have a severe cervical vertebral injury, as respiratory involvement can occur gradually and very insidiously, even when there is apparently only limited or no neurological involvement below the spinal injury site; and exhaustion of other respiratory compensatory muscles (abdominal, intercostal and accessory) can also occur. Weakness of such muscles as the deltoid or the biceps must be carefully and repeatedly watched for if there is the least doubt concerning respiratory involvement. 


\section{RÉSUMÉ}

Une lésion complexe vertébro-ligamentaire de la colonne cervicale en $\mathrm{C}_{4}-\mathrm{C}_{5}$, associée à des troubles moteurs et sensitifs suspendus, est présentée. La lésion traumatique était due à un méchanisme d'élongation et de rotation violente survenue au cours d'une manoeuvre inhabituelle d'un chariot élévateur mécanique. La principale atteinte était d'ordre vitale par paralysie bilatérale des deux nerfs phréniques nécessitant une assistance ventilatoire contrôlée pendant deux semaines. Les différents mécanismes pathogéniques concernant l'atteinte des deux nerfs phréniques sont discutés.

\section{ZUSAMMENFASSUNG}

Es wird ein Fall von Luxationsf raktur der Halswirbelsaüle (4. und 5. Halswirbel) mit Motor- und Empfindungsstörungen beschrieben. Der Schaden wurde während der Bedienung eines Hebegeräts durch Verziehung und Verdrehung verursacht. Die wesentliche Folgen waren eine Lähmung des Zwerchfells die eine künstliche Beatmung von zwei Wochen erförderlich machte. Die verschiedenen Mechanismen die für diese Lähmung in Betracht kommen, sind zur Diskussion gestellt.

\section{REFERENCES}

Guttmann, L. (1973). Spinal cord injuries, comprehensive management and research. Blackwell Scientific Publications. p. 262. 